\title{
What do the Examiners Understand by Formulation?
}

\author{
A Survey of the Members of the College's Board of Examiners
}

\author{
JUlie A. Hollyman, Clinical Research and Honorary Senior Registrar and LoIC Hemsi, Consultant Psychiatrist, St \\ George's Hospital Medical School, London SW 17
}

A recent survey of the views of clinicians at St George's Hospital on the content of the psychiatric formulation (Hollyman and Hemsi, 1983) revealed much diversity of opinion and confirmed our hypothesis that the notion is open to different interpretations. It seemed appropriate therefore to conduct a similar survey of College Examiners to discover whether there is similar variation in that group.

The President, Professor Rawnsley, and the Chief Examiner, Professor Cawley, agreed that such a survey be carried out and this was done in October 1982.

\section{Method}

The methods for the survey and the analysis were the same as those used on the first occasion (Hollyman and Hemsi, 1983).

\section{Results}

The response rate was 48 per cent. Three of the replies could not be analysed because of the manner in which they were worded. The Table (column a) indicates the percentage of examiners who made reference to the stated individual items in their answers.

History, diagnosis, management and prognosis scored highly. There was a marked preference for differential diagnosis as against single diagnosis. Physical examination and psychodynamics were generally excluded from the formulation. There was no consensus about the place of mental state, investigations, aetiology and length.

\section{Discussion}

The results of this second survey show that a diversity of views on the psychiatric formulation is also present among the 48 per cent of examiners who replied to the survey letter. The response rate was substantially lower than in the St George's survey and there can be no certainty as to how representative the responders were of all the examiners. A number of those who replied stated that they were pleased that the subject was being studied as they themselves saw it as an area of difficulty when they examined. This is of particular importance in as much as the inability to present a coherent formulation appears to be the chief reason for failure in the MRCPsych examination (Reveley, 1983). The uncertainty regarding the interpretation of the responses is therefore all the more unfortunate. It is possible that those who did not reply do not regard the formulation as a contentious area, or that they have no rigid views as to what it should contain and are therefore open to any version a candidate may offer; other reasons are of course possible. Although the examiners reached no consensus about including investigations in the formulation, they were much more likely to do so than the St George's psychiatrists (Hollyman

TABLE

Inclusion of items in formulation - comparison of examiners with other groups

(a)

Item

\begin{tabular}{l} 
\\
\\
\hline History \\
Mental state \\
Physical examinatiom \\
Investigations \\
Differential diagnosis \\
Single diagnosis \\
Psychodynamics \\
Aetiology \\
Management \\
Prognosis \\
Length
\end{tabular}

(b)

St George's

pre-membership

trainees (c)

St George's

consultants

(\%)
(\%)

(\%)

78

62

62
7

49

80

11

29

60

82

69

51

$\begin{array}{ll}81 & 81 \\ 38 & 57 \\ 13 & 10 \\ 13 & 33 \\ 50 & 76 \\ 37 & 24 \\ 19 & 33 \\ 56 & 43 \\ 81 & 81 \\ 69 & 67 \\ 44 & 29\end{array}$


and Hemsi, 1983). Forty-seven per cent of examiners included investigations, compared with 27 per cent of the total St George's sample. Similarly, a higher proportion (51 per cent) of the examiners showed interest in the length of the formulation than of the St George's sample (27 per cent).

The examination itself is probably responsible for the latter difference, as the examiner will wish the candidate to produce a formulation which is of sufficient length to provide a basis for discussion, but also brief enough to allow time for this. Like the St George's consultants, the examiners had different views on the ideal length of a formulation. Some respondents expressed a 'written' length and some a 'spoken' length, and this hampered comparisons. There, was a tendency for examiners to favour a formulation of 'five to ten minutes' which may be equivalent to the fairly frequently mentioned 'half or 'one side' of A4 paper. However, there were extreme views within the group, one examiner preferring 'two minutes' and another giving an example which was almost two sides of A4 paper in length. The views of the examiners were compared with those of the pre-membership trainees in the St George's group, as major differences between the two groups would be the source of problems in the examination (Table, columns (a) and (b) ).

The results revealed ample scope for difficulty. There was agreement between the examiners and the trainees to include history. management and prognosis in the formulation and to exclude physical examination and psychodynamics. Similar proportions of the two samples were concerned with aetiology (examiners 60 per cent, trainees 56 per cent and with length (examiners 51 per cent, trainees 44 per cent); nevertheless, as the figures do not represent a consensus view within either group, there is still a potential difficulty in the examination should an examiner meet a trainee with a different view of the formulation. Most striking, however, were areas of clear difference about the inclusion of mental state, differential diagnosis and investigations. The trainees were much less likely to include mental state and investigations in their formulations (38 per cent and 13 per cent respectively) than the examiners (62 per cent and 49 per cent respectively). In addition, the examiners placed much greater emphasis on a differential diagnosis ( 80 per cent) as opposed to a single diagnosis (11 per cent) than did the trainees, of whom only 50 per cent included a differential diagnosis, 37 per cent preferring a single diagnosis. Similar differences existed between the trainees and their teachers at St George's (Table, columns (b) and (c)). If current College examiners were excluded from the group of St George's consultants, then the differences were less marked and fewer consultants included mental state (47 per cent), investigations ( 24 per cent) and differential diagnosis ( 71 per cent) in their replies.

If these results are typical of pre-membership trainees and their teachers in other parts of the country and if the sample of examiners is at all representative, then it seems that there is a serious difference between the view of formulation being taught by consultants to their trainees and that expected by the examiners in the actual examination. This would explain what, in our experience, is the common disagreement between examiner and candidate in the clinical examination, as to what constitutes a formulation. We were interested to see the paper by Varghese and Mellsop (1983) which studied the views of Australian and New Zealand examiners on the formulation. Their method differed from that used here and the two surveys are not fully comparable. Forty senior Australian and New Zealand psychiatrists who had examined postgraduates were asked to assess twelve specimen formulations; twenty-four ( 60 per cent) responded.

Reasonable concordance between the examiners was demonstrated. This contrasts with the lack of consensus found in our studies, but the examiners in Australia and New Zealand were not asked to state an 'ideal formulation', although they were able to comment as they wished. Ten of the twenty-four examiners did give their views on the content of the formulation and Varghese and Mellsop comment that there was 'considerable disagreement on the length and the kind of information to include.' This suggests that differences of opinion might have come to light if the survey method had been the same as used by the present authors for examiners in the British Isles.

In view of the importance reported to be accorded to the formulations in the MRCPsych examination (Reveley, 1983) and of the evidence that both in the Australasian and in the British Colleges examiners are divided in their views on the content of the formulation, some action in this area appears to be required from examining bodies. This could take the form of clear and specific guidelines, which could be communicated to trainees as soon as they enter psychiatry rather than immediately before the examination. Such a policy would carry the risk of undue rigidity and regimentation, highly undesirable in psychiatric practice. An alternative, which seems to the authors to be preferable, would be for examiners always to indicate clearly during the examination the information which they are seeking at each point.

\section{REFERENCES}

Hollyman, J. A. \& Hemsi, L. (1983) What do psychiatrists understand by formulation? A survey of clinicians in a group of hospitals in London. Bulletin of the Royal College of Psychiatrists, 7, 140-43.

Reveley, A. (1983) Why do candidates fail the MRCPsych Part II? Bulletin of the Royal College of Psychiatrists, 7, 51 .

Varghese, F. T. \& Mellsop, G. W. (1983) Formulating a psychiatric case. Bulletin of the Roval College of Psychiatrists, 7, 48-50. 